\title{
UTILIZAÇÃO DO CICLO PDCA E APLICAÇÃO DO MILK RUN EM UM PROCESSO DE LOGÍSTICA REVERSA EM UMA INDÚSTRIA DE ALIMENTOS
}

\section{USE OF THE PDCA CYCLE AND MILK RUN APPLICATION IN A REVERSE LOGISTICS PROCESS IN A FOOD INDUSTRY}

\author{
Johnatan Correia Mantay de Paula ${ }^{1}$, \& Rita de Cassia Feroni ${ }^{2}$ * \\ ${ }^{12}$ Centro Universitário Norte do Espírito Santo da Universidade Federal do Espírito Santo. \\ ${ }^{1}$ correia.johnatan@gmail.com ${ }^{2 *}$ ritaferoni@gmail.com
}

\section{ARTIGO INFO.}

Recebido em: 26.02.2021

Aprovado em: 10.04.2021

Disponibilizado em: 30.04.2021

\section{PalaVRaS-ChaVe:}

Logística reversa; PDCA; Milk Run; satisfação do cliente

\section{KEYWORDS:}

Reverse Logistic; PDCA; Milk Run; Customer satisfaction

*Autor Correspondente: Feroni, R. de C.

\section{RESUMO}

A logística reversa vem se destacando dentro das organizações como uma estratégia empresarial, que além de apoiar-se em aspectos legais e socioambientais, procura a satisfação dos clientes. Assim, o presente estudo analisou a logística reversa em uma indústria do ramo alimentício objetivando gerar soluções práticas e viáveis para o problema de insatisfação dos principais clientes da organização, motivados pela ineficiência dos processos reversos. Para tanto, utilizou-se a metodologia PDCA como norteadora central na resolução do problema proposto, bem como a técnica milk run como ação principal do trabalho. Como resultados, obtém-se maior eficiência no processo de logística reversa, pautado em quatro principais indicadores: i) maior rapidez no retorno de mercadorias de devoluções por causa de uma consolidação de carga mais rápida devido a aplicação do milk run; ii) redução de custos de frete reverso na região Sul motivados pela negociação realizada pautando principalmente a centralização dos volumes em uma mesma transportadora; iii) aumento no nível de satisfação dos principais clientes da organização; iv) maior reaproveitamento dos produtos retornados devido a maior agilidade nesse processo reverso.

\begin{abstract}
Reverse logistics has stood out within the associations as a business strategy, which in addition to supporting itself in legal and socio-environmental aspects, seeks customer satisfaction. Thus, the present study analyzed the reverse logistics in a food industry aiming to generate practical and viable solutions to the problem of dissatisfaction of the main customers of the organization, motivated by the inefficiency of the reverse processes. Therefore, the PDCA methodology was used as the central guideline in solving the proposed problem, as well as the milk run technique as the main action of the work. As a result, results are greater efficiency in the reverse logistics process, based on four main indicators: i) faster return of returns products due to faster load consolidation due to the application of the milk run; ii) reduction of reverse freight costs in the South region motivated by the negotiation carried out, mainly based on the centralization of volumes on the same carrier; iii) increase in the level of satisfaction of the organization's main customers; iv) greater reuse of the returned products due to greater agility in this reverse process.
\end{abstract}


Citação (APA): de Paula, J. C. M., \& Feroni, R. de C. (2021). Utilização do ciclo PDCA e aplicação do milk run em um processo de logística reversa em uma indústria de alimentos. Brazilian Journal of Production Engineering, 7(2), 16-30.

\section{INTRODUÇÃO}

Técnicas de gestão de operações (GO) podem influenciar positivamente na diminuição dos custos de uma empresa (Nisiyama, Oyadomari, Yen-Tsang, Aguiar, 2016). Dentre as áreas de atuação da GO destaca-se a logística e a cadeia de suprimentos (Peinado \& Graeml, 2016), uma vez que, diante de um cenário extremamente competitivo e de constante mudança, torna-se vital planejar (e quando necessário replanejar) a produção, gerenciar a demanda e a oferta à fim de sanar a necessidade do cliente.

Segundo Vergara e Yamanari (2016) as empresas devem manter um nível de serviço elevado em todos os processos logísticos, incluindo inclusive, o processo de retorno de produtos pósvenda. Nesse sentido, a logística reversa aparece como o fechamento de uma cadeia de suprimentos, incluindo a reutilização, remanufatura e ou reciclagem de materiais em novos materiais ou produtos com valor no mercado (Sathiyagothai \& Saravanan, 2017). Destaca-se neste contexto, requisitos legais regidos pela Lei n. 12.305 (2010), mas nota-se também que a logística reversa dentro de uma empresa, pode estar associada ao aumento de eficiência, redução de custos com a aquisição de matéria-prima virgem e ao aumento das margens de lucro (Sathiyagothai \& Saravanan, 2017), além de agregar valor à cadeia de suprimentos, com responsabilidade ambiental e melhora na forma como a empresa é vista pelos consumidores (Faria \& Santos, 2020).

Dessa forma, a logística reversa deixa de ser apenas um requisito legal ou socioambiental e começa a permear na estratégia empresarial, de maneira a se tornar um fator de sucesso organizacional. Por outro lado, pode-se destacar obstáculos envolvendo a logística reversa, como dificuldades em realizar previsões, necessidade de mais pontos de distribuição e equipamentos, embalagens que possam ser danificadas, preços incertos, ciclo de vida dos produtos não determinado e baixa transparência e rastreabilidade (Sathiyagothai \& Saravanan, 2017). Destaca-se nesse contexto a implantação da logística reversa em indústrias alimentícias, uma vez que as indústrias desse setor podem ser responsáveis pela destinação dos resíduos de toda a cadeia, desde a aquisição de matéria-prima até mesmo o recolhimento de produtos por motivos como, validade que expirou, qualidade de embalagem, recall ou ainda não aceitação do produto pelo mercado, gerando custos elevados e necessidade de uma estrutura de suporte para executar essa operação (Faria \& Santos, 2020).

Para dar suporte a melhoria de processos, metodologias como o ciclo PDCA (planejar, fazer, checar e agir) podem ser utilizadas. Essa metodologia vem sendo utilizada em trabalhos aplicados a logística e a logística reversa. Silva (2013) destaca que ferramentas como o ciclo PDCA podem oferecer um diferencial competitivo às empresas do ramo logístico para que se mantenham no mercado, uma vez que possibilitam a empresa identificar processos que possuem falhas e possíveis correções. Melo e Ribeiro (2015) e Santos e Galan (2017), encontraram resultados satisfatórios com a aplicação do PDCA no setor de logística, sendo que o primeiro aumentou o desempenho operacional por meio da redução de atrasos na liberação de caminhões e, o segundo, ao determinar a margem de ociosidade de cada atividade do setor de carregamento e expedição estudada, realizou ajustes para um novo plano. Moreira e Alves (2020), avaliaram como o processo de logística reversa de pós-venda gera impacto em uma entidade corporativa, 
verificando que o desvio que mais acarretou a ocorrência de logística reversa foi a incidência de avarias e que o desacordo comercial foi o item que mais promoveu impacto financeiro no processo de logística reversa da empresa.

Após a identificação de um problema no processo de logística reversa, a ação para a melhoria pode ser tomada utilizando um modelo como o milk run. Esse modelo já aplicado a logística direta pode também ser viável quando aplicado no sentido reverso, uma vez que segundo Moura e Botter (2016) a partir do modelo milk run envia-se um veículo por uma rota definida parando em vários pontos de coleta de material que seguirão para um ponto de destino em comum. Estudo realizado por Reis, Carmo e Nishioka (2008), verificou que a partir do uso do milk run a empresa poderia ter um melhor relacionamento com os seus fornecedores além de uma otimização de rotas e dos veículos. Amaral, Bonato, Pereira, Schroeder e Abrita (2018) verificaram a redução nos custos com o transporte logístico a partir da utilização do milk run.

Dessa forma, o presente trabalho tem como objetivo investigar a logística reversa em uma indústria do setor alimentício de grande porte, por meio do PDCA, e propor ações de melhoria de eficiência, norteada pela implementação do milk run como uma alternativa prática e viável para realização do retorno de produtos provenientes de devoluções dos clientes.

\section{Metodologia}

A empresa em estudo é uma multinacional do ramo alimentício, situada na região centro-oeste do Brasil. Seu raio de atuação estende-se por todo o território brasileiro, com uma gama de produtos provenientes do processamento de tomates e vegetais, bem como, condimentos diversificados para o atendimento de seus clientes no modelo B2B. Por questões de sigilo, serão suprimidas do presente trabalho, informações que possam identificar e detalhar a gestão da produção da empresa em estudo.

A presente pesquisa iniciou-se com a coleta de dados a partir de análise de documentos da empresa, bases de dados históricos, entrevistas com os gestores e colaboradores envolvidos nos processos logísticos, industriais e comerciais e no acompanhamento das rotinas de produção e logística.

Dando sequência ao trabalho, utilizou-se, para o controle e melhoria do processo a metodologia PDCA. A primeira macroetapa do PDCA está relacionada ao Planejar, aqui dividida em quatro microetapas, sendo elas: i) identificação do problema: a partir do diagrama de Pareto, e o indicador chamado Net Promoter Score (NPS) que segundo Oliveira, Vieira e Kovaleski (2016), trata-se de um método simples que além de verificar o grau de satisfação dos clientes possibilita identificar pontos específicos de melhoria no produto e no processo; ii) análise do fenômeno: onde foram mapeados os processos e levantados os dados para análise; iii) análise do processo: onde utilizou-se de um brainstorming com os funcionários do setor e, em seguida, utilizou-se o diagrama de Ishikawa; iv) estabelecimento da meta: baseou-se na metodologia SMART, ou seja, uma meta específica, mensurável, atingível, relevante e temporal; e v) elaboração de planos de ação: realizando-se a priorização dos problemas focos a serem resolvidos por meio de uma matriz GUT (acrônimo de gravidade, tendência e urgência) e criouse planos de ação norteados pela técnica gerencial $5 \mathrm{~W} 2 \mathrm{H}$, simplificação dos seguintes

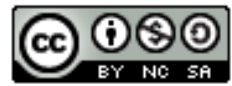


parâmetros: o que (what), por que (why), onde (where), quando (when), quem (who), como (how) e quanto custa (how much). A utilização de algumas dessas ferramentas também pode ser encontrada nos estudos de Melo e Ribeiro (2015) e Moreira e Alves (2020). Nesta etapa, a fim de buscar o aumento de eficiência através da logística reversa, como abordado em Sathiyagothai e Saravanan (2017), aplicou-se o milk run como ferramenta.

A segunda macroetapa refere-se ao Fazer, aqui dividida em duas microetapas, sendo elas: i) treinamentos: onde foram elaborados planos de divulgação e conscientização para todos os envolvidos com os planos de ação; e ii) execução: em que se gerenciou e controlou-se as ações pré-estabelecidas na etapa anterior.

A macroetapa seguinte, consiste em Verificar, onde se checou se a etapa anterior foi realizada da melhor maneira possível e, também, se as ações estipuladas foram suficientes para atingir a meta pré-estabelecida na primeira etapa, Planejar. Utilizou-se, para isso, a verificação do grau de redução do problema inicial, bem como, quais planos de ação não haviam sido executados, ou executados da melhor maneira possível, e quais poderiam ser melhorados. Os meses de outubro e novembro de 2019 foram escolhidos para se realizar a coleta de dados dessa etapa.

Como última etapa tem-se o Agir. Essa etapa constituiu-se em instituir o novo modelo estabelecido nas etapas anteriores como modelo usual padrão da organização, bem como, a formalização da documentação desse novo modelo e, por fim, o treinamento e disseminação do novo padrão estabelecido.

\section{RESULTADOS}

Os resultados encontram-se subdivididos a partir das etapas do PDCA supracitadas.

\section{Etapa Planejar}

Inicialmente, levantou-se a hipótese de que os clientes estavam insatisfeitos com os processos relacionados a logística reversa da empresa. Necessitou-se então entender qual a percepção deles sobre os processos logísticos. O Key Performance Indicator (KPI) utilizado atualmente pela empresa para essa verificação é o Net Promoter Score (NPS). Esse KPI é medido trimestralmente com os principais clientes da empresa, chamados de Key Account (KA), por meio de uma entrevista estruturada, na qual eles avaliam a performance da empresa em cada tópico solicitado.

Dessa forma, ao verificar esse KPI, percebeu-se que os clientes estavam insatisfeitos com os processos de logística reversa. O estudo de Oliveira et al. (2016) evidencia que a classificação dos clientes como detratores não é satisfatória para uma empresa, uma vez que, com base nos pressupostos do NPS os clientes podem tomar uma postura de criticar a empresa analisada. Além disso, há campos de perguntas abertas em que os respondentes do NPS podem indicar quais os principais problemas ocorridos durante o período avaliado. Para entender melhor esses problemas, foram criadas categorizações e as respostas dadas por eles foram classificadas entre essas categorias, como pode ser visto na Figura 1. A Figura 1 indica que $63 \%$ dos problemas relatados correspondiam a duas categorias: i) demora no pagamento de notas fiscais de

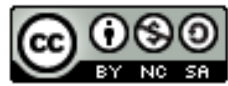



reversa em uma indústria de alimentos. Brazilian Journal of Production Engineering, 7(2), 16-30.

devoluções parciais (NFDPs); e ii) demora na realização de coletas de produtos devolvidos pelos clientes.

Figura 1. Categorias de problemas enfrentados pelos Key Account (KA) respondentes.

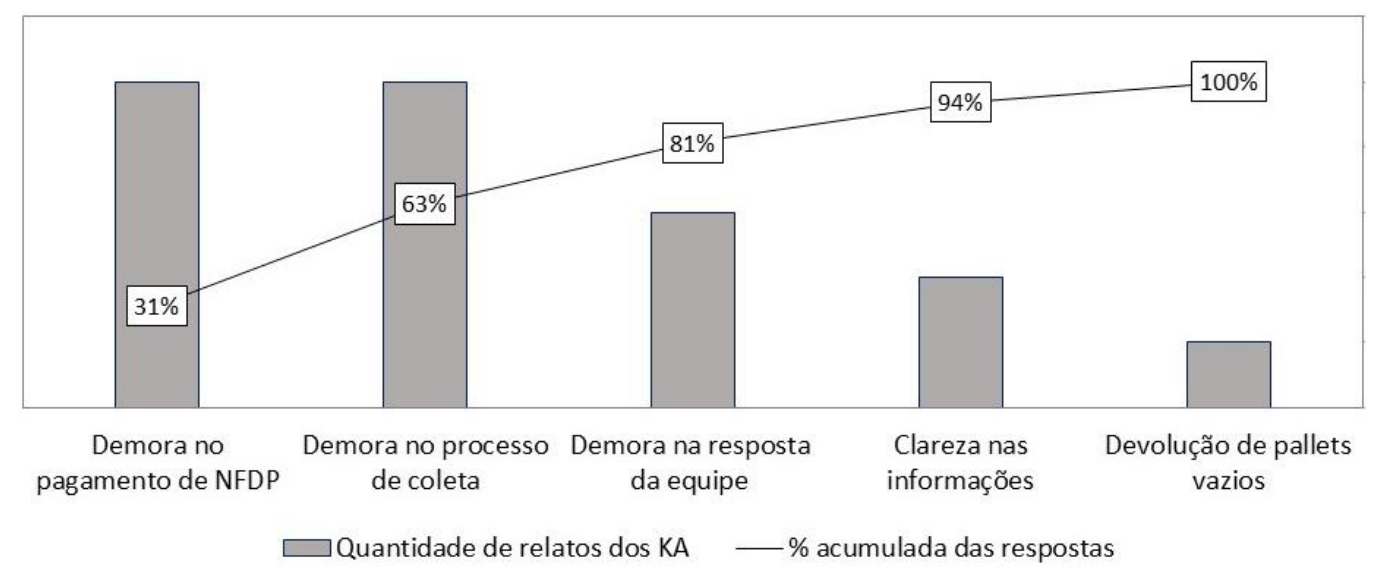

Fonte: Elaborado pelo autor.

Dessa forma, confirmou-se a hipótese inicial de que havia um problema na logística reversa que gerava insatisfação dos clientes. As duas categorias de problemas destacados estão ligadas ao fator rapidez. Verificou-se também que elas possuem relação entre si, uma vez que, segundo as diretrizes e as políticas da empresa, i) não é autorizado o descarte de mercadorias na ponta, ou seja, para realizar descartes das mercadorias elas devem retornar aos centros de distribuição (CDs) da empresa; e 2) as NFDPs são pagas aos clientes apenas após retornarem aos CDs. Dessa forma, para resolução do problema foi proposto modificar o processo, minimizando o lead time.

O fluxograma da Figura 2 apresenta simplificadamente as etapas que ocorrem desde o momento em que se fatura e segrega-se o pedido do cliente (logística direta) até os processos de logística reversa finalizados pelo pagamento da NFDP emitida. Assim, destaca-se, em relação a logística reversa, para o presente estudo: i) tempo de consolidação de carga, dado pela média em um intervalo de tempo, entre a diferença da data de saída de um parceiro logístico em direção ao CD e a data em que é emitida uma NFDP, que corresponde a $85,25 \%$ do tempo total; ii) tempo de trânsito, dado pela média em um intervalo de tempo, entre a diferença da data de recebimento do veículo no $\mathrm{CD}$ e a data de saída de um parceiro logístico em direção ao $\mathrm{CD}$, que corresponde a 6,55\% do tempo total; e iii) tempo de processos internos de pagamento, que corresponde a $8,20 \%$ do tempo total. Para executar todas as etapas da logística reversa a organização necessitava de um tempo elevado, o que gerava insatisfação dos clientes, principalmente, devido ao seu capital investido estar parado.

Verificando-se onde se encontrava o maior tempo do processo, buscou-se, junto aos gestores, levantar as variáveis que poderiam influenciar diretamente nesse tempo, sendo selecionadas as seguintes: i) as regiões do país atendidas e seus respectivos volumes de vendas e de devoluções de mercadorias; ii) o lead time de retorno de mercadorias de cada região; iii) o volume necessário para consolidação de carga para retorno de mercadorias; iv) a quantidade e a localização dos parceiros logísticos em que as mercadorias de devoluções poderiam ser armazenadas até a consolidação de carga; e v) os custos operacionais de retorno de mercadoria. 
Citação (APA): de Paula, J. C. M., \& Feroni, R. de C. (2021). Utilização do ciclo PDCA e aplicação do milk run em um processo de logística reversa em uma indústria de alimentos. Brazilian Journal of Production Engineering, 7(2), 16-30.

A partir do levantamento dessas variáveis, optou-se por agrupar as regiões atendidas pela empresa por regionais, sendo elas, Regional Norte Nordeste (região norte e nordeste do país), Regional Sul (região sul do país), Regional Centro Oeste (região centro-oeste do país), Regional Sudeste (região sudeste do país, com exceção do estado de São Paulo) e São Paulo (estado de São Paulo). Após o levantamento e organização dos dados de volume de devoluções e lead time das regionais, obteve-se, respectivamente, a Figura 3, que detalha o volume de devoluções parciais por estado/regional, onde quanto mais azul escuro, maior o volume de devoluções, e a Tabela 1 que mostra um patamar do lead time por regionais em dias, sendo o tempo associado a $\mathrm{X}$ dias de referência.

Figura 2. Etapas para o retorno da mercadoria utilizadas na empresa.

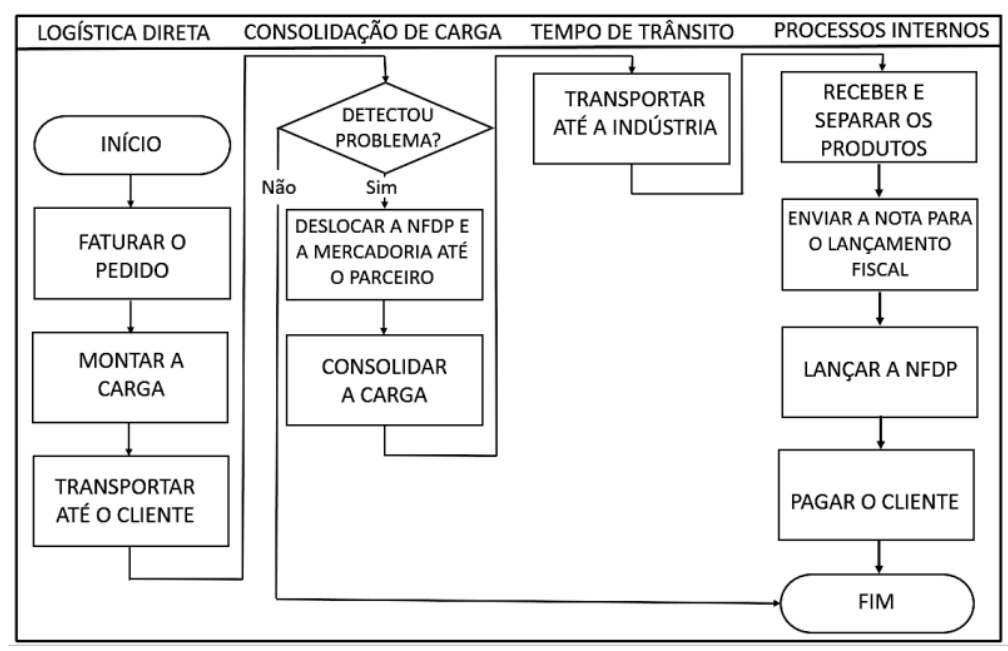

Fonte: Autores.

Figura 3. Volume de devoluções parciais por regional.

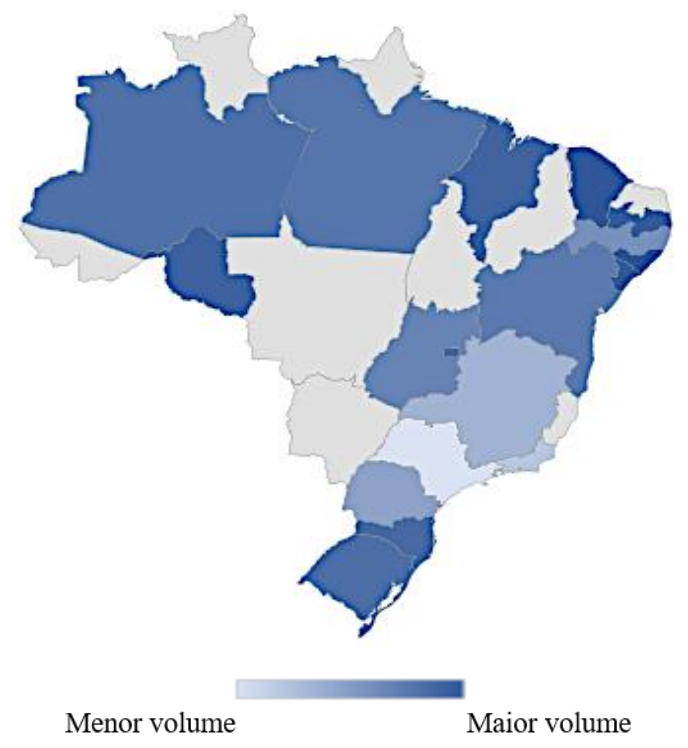

Fonte: Autores.

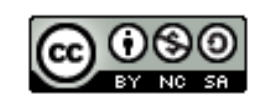



reversa em uma indústria de alimentos. Brazilian Journal of Production Engineering, 7(2), 16-30.

Tabela 1. Lead time por regionais onde X representa a quantidade de dias de referência.

\begin{tabular}{c|c}
\hline Regional & Lead Time \\
\hline Sul & $\mathrm{X}$ \\
\hline Norte Nordeste & $\mathrm{X}+3$ \\
\hline Centro Oeste & $\mathrm{X}-1$ \\
\hline Sudeste & $\mathrm{X}-6$ \\
\hline São Paulo & $\mathrm{X}-12$ \\
\hline
\end{tabular}

\section{Fonte: Autores.}

Portanto, o maior lead time de retorno, corresponde a regional Norte Nordeste, porém, esse tempo é influenciado pelo tempo de trânsito elevado devido as distâncias e as estradas dos estados presentes nessa regional, como foi verificado no levantamento junto a empresa. Como o foco do projeto é no tempo de consolidação, o maior tempo entre os três analisados, optou-se analisar a regional com o segundo maior lead time de retorno, a Sul. Vale ressaltar que esse tempo da regional Sul não era influenciado pela falta de volume para consolidação de carga, afinal, como pode ser observado na Figura 3, os três estados da regional Sul (Paraná, Santa Catarina e Rio Grande do Sul) estão em tons de cor na escala azul mais escuro.

O próximo passo, consequentemente, foi entender o motivo da regional ter essa ineficiência no que tange o quesito rapidez. Para esse entendimento, utilizou-se um grupo multidisciplinar das áreas da logística da organização para realização de um brainstorming. Por meio desse brainstorming, tornou-se possível a criação do diagrama de Ishikawa apresentado na Figura 4, onde o problema foco da discussão foi o tempo elevado na consolidação de cargas de devolução, obtendo, assim, suas principais causas em seis parâmetros diferentes (métodos, máquinas, meio ambiente, mão de obra, materiais e medidas) para compreender as causas do problema enfrentado. Ao se utilizar ferramentas como essa, busca-se a estratificação do problema e a identificação de suas causas principais para que uma solução seja alcançada (Melo \& Ribeiro, 2015).

Figura 4. Ishikawa dos possíveis problemas para o tempo elevado de consolidação das mercadorias de devolução.
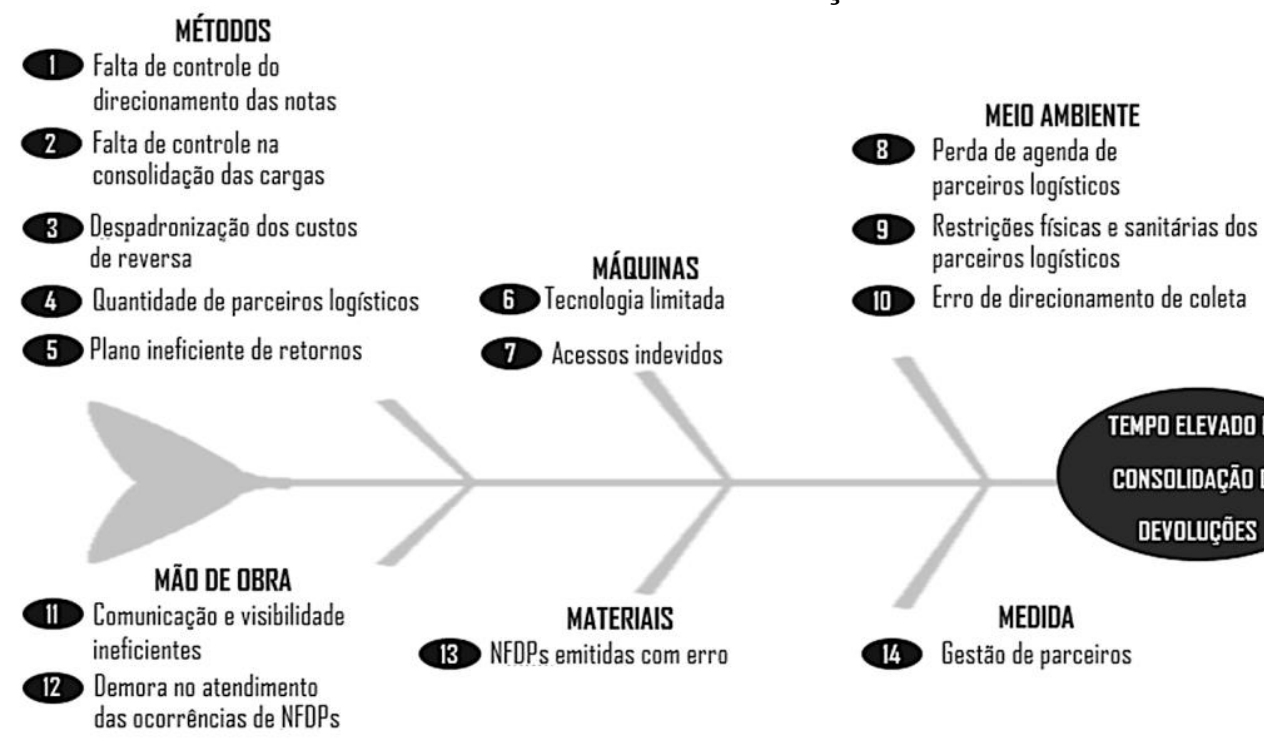

(6) Tecnologia limitad

(10) Erro de direcionamento de coleta

(7) Acessos indevidos

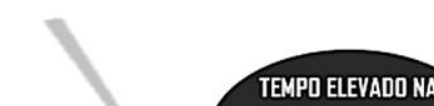
CONSOLIDAÇÃODE DEVOUCUÉES

Fonte: Autores. 

reversa em uma indústria de alimentos. Brazilian Journal of Production Engineering, 7(2), 16-30.

Finalizadas todas as análises supracitadas e entendendo as causas raízes do problema, bem como as restrições do projeto, o próximo passo foi a definição da meta a ser alcançada. Para tanto, levou-se em consideração às análises anteriores e a opinião dos gestores da logística da organização. Essa meta foi estipulada baseada na metodologia SMART, assim, chegou-se a uma meta específica, mensurável, atingível, relevante e temporal, sendo ela, reduzir em $49 \%$ o lead time médio, associado ao tempo $\mathrm{X}$ (Tabela 1) para o retorno das mercadorias de todas as NFDPs emitidas no mês de outubro de 2019 da regional Sul.

Definida a meta e levantadas todas as causas do problema apresentado na Figura 4, realizou-se uma priorização utilizando a matriz GUT para definir os problemas que seriam focados, com atribuições de pontos em uma escala conforme mencionado em Meireles (2001). Para o presente trabalho, o intervalo de pontos de 1 a 5 , resultou em uma nota 5 para os casos onde o impacto da causa é extremamente negativo até a nota 1, onde o impacto é pouco expressivo. Dessa forma, ao levantar a média das notas dadas pelos gestores envolvidos, gerou-se a Tabela 2, que apresenta o tipo de problema, e os parâmetros da Figura 4 que estão ligados ao problema, e suas respectivas notas de gravidade, urgência e tendência e, além da pontuação total e se esse problema será tratado como prioridade ou não. Desse modo, devido ao prazo para a execução do projeto, decidiu-se focar nos problemas que foram denominados como classe A e classe B.

Tabela 2. Priorização dos problemas focais no projeto (matriz GUT).

\begin{tabular}{|c|c|c|c|c|c|c|}
\hline Tipo & Causa & 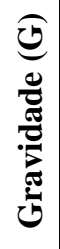 & 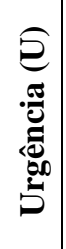 & 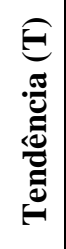 & 苞 & \\
\hline Medidas & Gestão de parceiros logísticos & 5 & 5 & 5 & 125 & $\mathbf{A}$ \\
\hline Método & Falta de controle no direcionamento das NFDPs & 5 & 5 & 5 & 125 & $\mathbf{A}$ \\
\hline Método & Plano eficiente de retornos & 5 & 5 & 5 & 125 & $\mathbf{A}$ \\
\hline Método & Falta de controle na consolidação de carga & 5 & 5 & 4 & 100 & $\mathbf{B}$ \\
\hline Método & Quantidade de parceiros logísticos & 5 & 3 & 4 & 60 & B \\
\hline Método & Despadronização de custos de reversa & 4 & 5 & 3 & 60 & $\mathbf{B}$ \\
\hline Mão de obra & Comunicação e visibilidade ineficiente & 4 & 3 & 5 & 60 & $\mathbf{B}$ \\
\hline Mão de obra & Demora no atendimento das ocorrências de NFDPs & 5 & 2 & 5 & 50 & $\mathbf{C}$ \\
\hline Máquinas & $\begin{array}{c}\text { Tecnologia limitada } \\
\end{array}$ & 4 & 3 & 4 & 48 & $\mathbf{C}$ \\
\hline Meio ambiente & Restrições físicas e sanitárias dos parceiros logísticos & 5 & 3 & 3 & 45 & $\mathbf{C}$ \\
\hline Materiais & Erros de emissão de NFDPs & 3 & 3 & 3 & 27 & $\mathbf{C}$ \\
\hline Meio ambiente & Perdas de agendamentos dos parceiros logísticos & 3 & 3 & 2 & 18 & $\mathbf{C}$ \\
\hline Meio ambiente & Erros de direcionamento de coleta & 4 & 2 & 2 & 16 & $\mathbf{C}$ \\
\hline Máquinas & Acessos indevidos & 3 & 2 & 2 & 12 & $\mathbf{C}$ \\
\hline
\end{tabular}

Fonte: Autores.

Para completar a etapa Planejar, reuniu-se novamente a equipe para um brainstorming para criação de planos de ação que mitigassem os problemas focais da Tabela 2. Os planos de ação gerados foram divididos em dois pilares: i) Processos e rotinas; e ii) Piloto, sendo o primeiro aplicado a todas as regionais, uma vez que envolve a reformulação e registros dentro da própria organização, e o pilar piloto apenas na regional Sul.

\section{Planos de ação no pilar de processos e rotinas}



reversa em uma indústria de alimentos. Brazilian Journal of Production Engineering, 7(2), 16-30.

Os planos de ação ligados ao pilar de processos e rotinas, dizem respeito a ações internas da organização para ter uma gestão mais eficiente das notas fiscais de devoluções parciais - NFDPs e suas respectivas mercadorias que ainda não retornaram à empresa. De modo geral, essas ações advindas do processamento do brainstorming, servem de suporte operacional e gerencial, englobando processos e rotinas que devem ser executados para garantir a rastreabilidade e maior controle no direcionamento das mercadorias para os parceiros logístico, dar visibilidade de onde se localizam essas mercadorias e o seus respectivos volumes, bem como, avaliar se os parceiros logísticos atuais supriam as necessidades em todas as regionais e, ainda, gerir o nível de serviço e de relacionamento com esses parceiros, como apresentado na Tabela 3.

Tabela 3. Causas e ações do pilar processos e rotinas.

\begin{tabular}{c|c}
\hline Causa & Plano de ação \\
\hline Falta de controle no direcionamento das NFDPs & Rotina D-1 \\
\hline Falta de controle no direcionamento das NFDPs & Farol de coletas \\
\hline Falta de controle na consolidação de carga & Sala de comando \\
\hline Quantidade de parceiros logísticos & Mapeamento de parceiros \\
\hline Gestão de parceiros logísticos & Manual para transportadores \\
\hline Comunicação e visibilidade insuficiente & Planilha do stress \\
\hline Gestão de parceiros logísticos & Integração de indicador \\
\hline
\end{tabular}

Fonte: Autores.

Os planos de ação criados nesse pilar estão apresentados na Tabela 4, baseado no $5 \mathrm{~W} 2 \mathrm{H}$ e consistem em: 1) na rotina D-1, onde levanta-se todas as NFDPs que foram emitidas no dia anterior, as trata e direciona ao parceiro logístico mais próximo, evitando direcionamentos equivocados realizados pela transportadora de entrega; 2) para o farol de coletas, criou-se uma planilha em que as solicitações de coletas eram priorizados de acordo com o seu tempo de emissão (do mais antigo para o mais recente), funcionando similar ao sistema kanban e, todas elas, tinham o prazo máximo de execução em 7 dias, com o objetivo de diminuir o segundo problema mais citados pelos NPS, a demora no processo de coleta; 3) a sala de comando foi uma planilha criada para gerar visibilidade a tudo que ainda não havia retornado a empresa e seus respectivos volumes dando suporte à decisão de retornar ou não uma carga; 4) para o mapeamento de parceiro, realizou-se o levantamento de todos dos parceiros atuais, levantou-se informações de restrições e, finalmente, criou-se um mapa online no qual aponta a localização de todos e os seus respectivos contatos responsáveis pela logística reversa; 5) a planilha do stress foi implementada com objetivo de dar visibilidade sobre as transportadoras que estavam gerando os maiores problemas da semana para que, assim, possibilitasse gerar ações para melhoria do nível de serviço; e 6) a integração de indicadores consistiu em criar critérios de avaliação para o nível de serviço reverso e integrá-lo aos KPIs já existentes da logística direta, assim, tal indicador influencia na quantidade de faturamento que é dado a determinada transportadora. Vale ressaltar que todas as ações não tiveram custo adicionais na sua implementação, por esse motivo a última coluna da Tabela 4 está sem valores. 
Citação (APA): de Paula, J. C. M., \& Feroni, R. de C. (2021). Utilização do ciclo PDCA e aplicação do milk run em um processo de logística reversa em uma indústria de alimentos. Brazilian Journal of Production Engineering, 7(2), 16-30.

Tabela 4. 5W2H dos planos de ação do pilar processos e rotinas.

\begin{tabular}{|c|c|c|c|c|c|c|}
\hline O que? & Por quê? & Onde? & Quando? & Quem? & Como? & $\begin{array}{l}\text { Quanto } \\
\text { custa? }\end{array}$ \\
\hline Rotina D-1 & $\begin{array}{c}\text { Direcionamento } \\
\text { eficiente das NFDPs }\end{array}$ & $\begin{array}{l}\text { Organização } \\
\text { em estudo }\end{array}$ & out/19 & $\begin{array}{l}\text { Setor de } \\
\text { logística } \\
\text { reversa }\end{array}$ & $\begin{array}{c}\text { Rotina de tratar todas } \\
\text { as notas emitidas no } \\
\text { dia anterior }\end{array}$ & - \\
\hline $\begin{array}{l}\text { Farol de } \\
\text { coletas }\end{array}$ & $\begin{array}{c}\text { Direcionamento } \\
\text { eficiente das NFDPs }\end{array}$ & $\begin{array}{l}\text { Organização } \\
\text { em estudo }\end{array}$ & out/19 & $\begin{array}{l}\text { Setor de } \\
\text { logística } \\
\text { reversa }\end{array}$ & $\begin{array}{l}\text { Planilha de ordem de } \\
\text { solicitação de coletas }\end{array}$ & - \\
\hline $\begin{array}{l}\text { Sala de } \\
\text { comando }\end{array}$ & $\begin{array}{c}\text { Visibilidade de } \\
\text { quando é possível } \\
\text { consolidar carga } \\
\end{array}$ & $\begin{array}{l}\text { Organização } \\
\text { em estudo }\end{array}$ & out/19 & $\begin{array}{l}\text { Setor de } \\
\text { logística } \\
\text { reversa } \\
\end{array}$ & $\begin{array}{c}\text { Planilha gerencial de } \\
\text { todas as NFDPs não } \\
\text { retornadas }\end{array}$ & - \\
\hline $\begin{array}{l}\text { Mapeamento } \\
\text { de parceiros }\end{array}$ & $\begin{array}{c}\text { Verificar se os nossos } \\
\text { parceiros eram } \\
\text { suficientes e } \\
\text { necessários }\end{array}$ & $\begin{array}{l}\text { Organização } \\
\text { em estudo }\end{array}$ & out/19 & $\begin{array}{l}\text { Setor de } \\
\text { logística } \\
\text { reversa }\end{array}$ & $\begin{array}{c}\text { Mapa online com } \\
\text { localização e contatos } \\
\text { do parceiro logístico }\end{array}$ & - \\
\hline $\begin{array}{c}\text { Manual para } \\
\text { transportadores }\end{array}$ & $\begin{array}{c}\text { Transparência e } \\
\text { orientação dos } \\
\text { processos a serem } \\
\text { seguidos pelos } \\
\text { transportadores }\end{array}$ & $\begin{array}{l}\text { Organização } \\
\text { em estudo }\end{array}$ & out/19 & $\begin{array}{l}\text { Setor de } \\
\text { logística } \\
\text { reversa }\end{array}$ & $\begin{array}{c}\text { Manual enviado via e- } \\
\text { mail para } \\
\text { transportadores }\end{array}$ & - \\
\hline $\begin{array}{l}\text { Planilha do } \\
\text { stress }\end{array}$ & $\begin{array}{c}\text { Fluidez da } \\
\text { comunicação do time } \\
\text { de logística reversa e } \\
\text { aumento de nível de } \\
\text { serviço dos transpores }\end{array}$ & $\begin{array}{l}\text { Organização } \\
\text { em estudo }\end{array}$ & out/19 & $\begin{array}{l}\text { Setor de } \\
\text { logística } \\
\text { reversa }\end{array}$ & $\begin{array}{c}\text { Planilha com os piores } \\
\text { casos de } \\
\text { transportadores }\end{array}$ & - \\
\hline $\begin{array}{l}\text { Integração de } \\
\text { indicador }\end{array}$ & $\begin{array}{c}\text { Integrar os KPIs de } \\
\text { nível de serviço } \\
\text { reverso aos KPIs de } \\
\text { logística }\end{array}$ & $\begin{array}{l}\text { Organização } \\
\text { em estudo }\end{array}$ & out/19 & $\begin{array}{l}\text { Setor de } \\
\text { logística } \\
\text { reversa }\end{array}$ & $\begin{array}{l}\text { KPI de mensuração de } \\
\text { nível de serviço } \\
\text { reverso baseado em } \\
\text { critérios pré-definidos }\end{array}$ & - \\
\hline
\end{tabular}

Fonte: Autores.

\section{Planos de ação do pilar piloto}

O pilar piloto aborda exclusivamente um plano de ação, baseado na utilização do milk run como alternativa para ganho de eficiência na regional Sul, como teste inicial para a logística reversa da organização, conforme apresentado no Tabela 5.

Tabela 5. Causas e ações do pilar piloto.

\begin{tabular}{c|c}
\hline Causa & Plano de ação \\
\hline Plano eficiente de retornos & Milk run \\
\hline Despadronização de custos de reversa & Milk run \\
\hline
\end{tabular}

Fonte: Autores.

Dessa forma, o milk run consiste basicamente em recolher mercadorias em mais de um posto de coleta (parceiro logístico), consolidando carga de maneira mais rápida. A execução do milk run foi planejada utilizando o Tabela 6.

Tabela 6. 5W2H do plano de ação do pilar piloto.

\begin{tabular}{c|c|c|c|c|c|c}
\hline O que? & Por quê? & Onde? & Quando? & Quem? & Como? & $\begin{array}{c}\text { Quanto } \\
\text { custa? }\end{array}$ \\
\hline Milk run & $\begin{array}{c}\text { Maior eficiência } \\
\text { nos retornos de } \\
\text { mercadorias }\end{array}$ & $\begin{array}{c}\text { Organização } \\
\text { em estudo }\end{array}$ & nov/19 & $\begin{array}{c}\text { Equipe de } \\
\text { projeto }\end{array}$ & $\begin{array}{c}\text { Criar um planejamento de } \\
\text { retorno coletando em mais } \\
\text { de um local as mercadorias }\end{array}$ & $\begin{array}{c}\text { Frete } \\
\text { reverso }\end{array}$ \\
\hline
\end{tabular}

Fonte: Autores. 

reversa em uma indústria de alimentos. Brazilian Journal of Production Engineering, 7(2), 16-30.

Portanto, a operação da logística reversa da regional Sul foi alterada do modelo atual de coleta e retorno direto do parceiro logístico, representado na Figura 5(a), para a nova abordagem dada pelo milk run, representado na Figura 5(b). Na Figura 5(a), verifica-se que, o cliente ao detectar um problema, emite uma NFDP e, tanto ela quanto sua mercadoria correspondente são levadas até o parceiro logístico mais próximo e, nesse parceiro, aguarda até que tenha um volume suficiente para retornar direto para a indústria, como mencionado anteriormente. Com a adoção do milk run, o esquema da Figura 5(b) mostra que, ao invés da NFDP e a mercadoria esperarem cada parceiro logístico consolidar a carga, roteiriza-se um trajeto em que um veículo, deslocase entre todos os parceiros coletando as mercadorias presentes em cada um deles para consolidar a carga de retorno.

Figura 5. Esquematização do modelo de retorno de mercadorias.

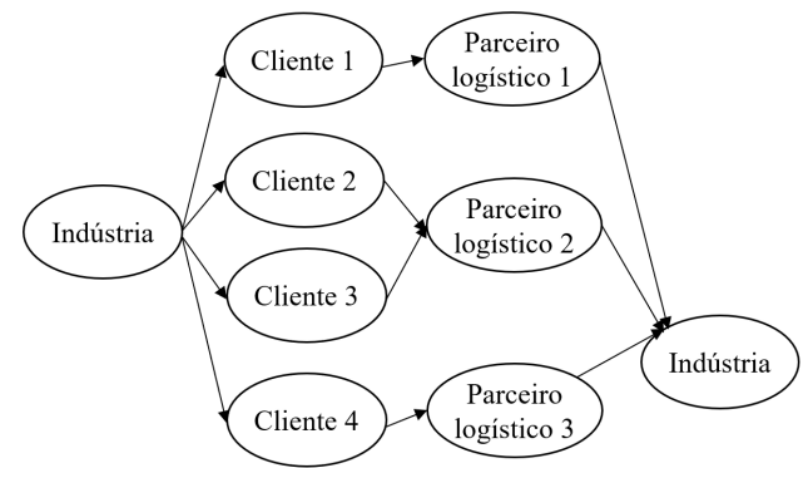

(a) Modelo Atual

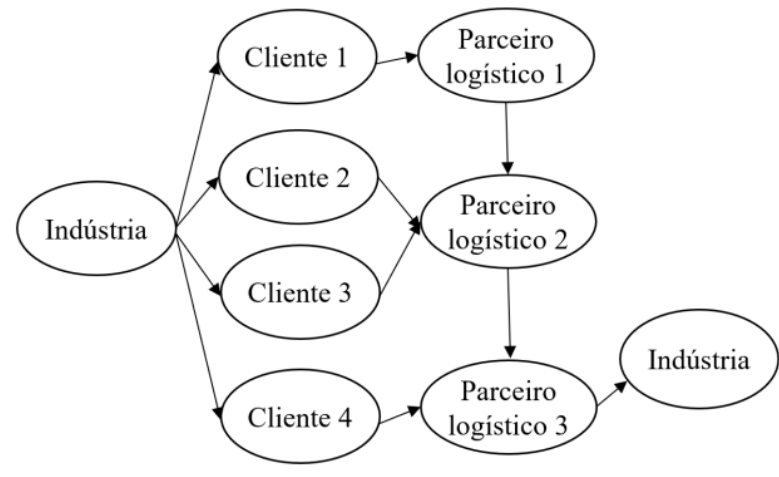

(b) Ferramenta milk run

\section{Etapa Fazer}

Fonte: Autores.

Sequencialmente, iniciou-se a macroetapa Fazer. Primeiramente, realizou-se todas as comunicações e divulgações necessárias sobre o plano. Internamente, para a equipe da logística reversa, foi realizada uma apresentação na qual evidenciou-se todo o problema, apresentou-se todas as análises supracitadas e, finalmente, como seria a execução de todos os planos propostos. Segundo Ngadiman, Moeinaddini, Ghazali e Roslan (2016), o sucesso na implementação da logística reversa em uma indústria de alimentos é influenciado por alguns fatores, entre eles, na fase inicial, deve-se apresentar os planos e conscientizar os funcionários, que a partir disso, podem compreender as práticas da engenharia reversa.

\section{Planos de ação do pilar processos e rotinas}

As ações desse pilar servem de suporte a operação, principalmente, para a aplicação do pilar piloto, por esse motivo ela foi de suma importância para o projeto.

A implementação desses planos de ação iniciou-se, a partir do levantamento mostrado na Tabela 4, com a criação da planilha de gestão da rotina D-1 e a criação da planilha online do farol de coletas, pois afetavam diretamente em uma das causas com pontuação máxima (a falta de controle no direcionamento das NFDPs). Simultaneamente, realizou-se a integração de indicadores e a planilha do stress (que era um dos parâmetros do indicador de nível de serviço reverso), bem como o manual dos transportadores, pelo mesmo motivo anterior, porém à fim 

reversa em uma indústria de alimentos. Brazilian Journal of Production Engineering, 7(2), 16-30.

de melhorar a gestão dos parceiros logísticos. Em seguida, criou-se e implementou-se a planilha de gestão (denominada sala de comando). Por fim, implementou-se o mapeamento dos parceiros para verificar se a quantidade de parceiros logísticos era suficiente e/ou necessária em todas as regionais.

\section{Planos de ação do pilar piloto}

Para o pilar piloto, além dos treinamentos supracitados nessa etapa, também, realizou-se um treinamento separado somente com a responsável pela regional Sul e, também, uma chamada de videoconferência na qual estavam presentes os responsáveis pela transportadora terceirizada escolhida para executar o piloto e os responsáveis pela logística reversa da organização em estudo, para realizar o alinhamento de como deveria ocorre a mudança operacional.

Dessa forma, a coleta de dados a partir da implementação do milk run ocorreu seguindo as premissas: (i) necessidade de duas rodadas de entrega mensais entre o parceiro logístico e a empresa, a fim de diminuir as chances de ocorrer um problema de indisponibilidade de veículos; (ii) a escolha da rota foi traçada baseada nas distâncias entre os parceiros e a indústria, diminuindo os custos de transporte, como mencionado em Setiani, Fiddieny, Setiawan e Etika (2017). A rota foi escolhida com o auxílio do Google Maps ${ }^{\circledR}$, ferramenta utilizada também no estudo de Amaral et al. (2018). Dessa forma, optou-se por iniciar a rota a partir do parceiro logístico mais distante da indústria, seguindo para os mais próximos e, em seguida, para a própria indústria, como pode ser visto no esquema da Figura 5(b); (iii) como restrição do sistema, as duas rodadas deveriam acontecer entre os dias 01 e 15 do mês subsequente a emissão da nota, pois ocorreu um alinhamento entre o setor de logística reversa e o setor de armazém. Assim, a primeira rodada ocorreu em 04 de novembro com todas as notas emitidas até o dia 15 de outubro. A segunda rodada ocorreu no dia 11 de novembro com todas as notas emitidas entre os dias 15 e 31 de outubro.

\section{Etapa Checar e Etapa Ação}

Ao finalizar a macroetapa anterior, iniciou-se a verificação dos pilares processos e rotinas e piloto, por meio de planilhas eletrônicas e dashboards de controle que apresentavam principalmente quais NFDPs haviam retornado e o lead time para realização desse retorno. Apenas no pilar piloto percebeu-se que houve um problema na operacionalização, pois durante a execução da primeira rodada, notou-se que uma das NFDPs gerada no primeiro dia do mês de outubro não havia retornado e, então, necessitou-se replanejar e agir para realizar a correção e, consequentemente, prevenir erros similares.

Portanto, criou-se uma ação para correção do problema com enfoque em ter maior controle sobre o que estava realmente retornando dentro do veículo que sairia em direção indústria. Essa ação foi um alinhamento com os parceiros logísticos e com a transportadora que executaria o milk run que sempre antes do veículo sair em direção a empresa, seria necessário um aval do setor de logística reversa, dessa forma, seria enviado via $e$-mail a relação de todas as NFDPs e itens que constavam dentro do veículo de transporte e a transportadora só poderia seguir o trajeto para indústria caso todos os itens solicitados constassem nessa relação. 
Finalizando, com as correções e alinhamentos necessários, executou-se, então, a segunda rodada, que retornou com todas as NFDPs emitidas entre 15 e 31 de outubro, bem como, com a NFDP que deveria ter chegado na primeira rodada.

\section{Resultados primários e secundários alcançados}

Dessa forma, para apurar se a meta: "reduzir em 49\% o lead time médio para o retorno das mercadorias de todas as notas emitidas no mês de outubro da regional Sul" havia sido atingida, compilou-se todos os dados necessários e, checou-se, primeiramente, o controle de NFDPs e mercadorias do centro de distribuição (CD) que apontou que $100 \%$ das NFDPs emitidas em outubro haviam retornado. Restava verificar se as NFDPs haviam retornado com o lead time médio reduzido como discutido no trabalho de Setiani et al. (2017). Para tal verificação, realizou-se a subtração entre o dia de chegada no CD (dia 04 ou dia 11 de novembro) e o dia em que a nota foi emitida pelo cliente (ou seja, o dia em que o cliente detectou o problema) e, em seguida, realizou-se a média desses valores encontrados, que foi comparada com a média anterior, igual a X. Ao realizar a comparação do lead time encontrou-se uma redução de 59\% no lead time com a utilização do milk run, ou seja, a meta estipulada foi cumprida. Essa maior porcentagem encontrada, melhorando o resultado em relação a meta, está associada ao fato de que a metodologia milk run foi aplicada em conjunto com as ações do pilar processos e rotinas, bem como, em parceria com a transportadora terceirizada, potencializando assim, os resultados adquiridos com o presente trabalho.

Além da mensuração realizada diante à meta estipulada, mensurou-se outros três reflexos secundários do projeto: i) o Net Promoter Score - NPS, ii) o custo de frete reverso, e iii) o reaproveitamento de mercadorias de devolução.

No primeiro aspecto, o NPS, mostrou um crescimento médio das notas relacionadas a logística reversa de 8,5\%, a nível Brasil, e de 28,3\%, na regional Sul. Esse aumento da nota recebida a nível Brasil ocorreu devido as ações do pilar processos e rotinas que foram aplicadas para todas as regionais, porém, na regional Sul, houve reflexo também da implementação do pilar piloto.

No segundo aspecto, o custo de frete reverso, obteve uma redução de $4 \%$ do frete médio realizado anteriormente na regional, pois segundo Setiani et al. (2017) o milk run é uma alternativa que permite redução de custos de transporte se comparado ao método de envio direto. Essa redução deve-se a visibilidade criada nas ações: i) mapeamento de parceiros (do pilar de processos e rotinas), e ii) no milk run, pois ao dar visibilidade ao time de suprimentos (responsáveis pelas negociações da organização) conseguiu-se chegar a um acordo de custo por tonelada menor que o praticado anteriormente com a transportadora escolhida, oferecendo maior volume e constância de carga a mesma, alinhado com os resultados encontrados por Moura e Botter (2016).

No terceiro aspecto, o reaproveitamento de mercadorias de devolução, uma das possibilidades de ações com os produtos de devolução quando retornam a indústria, comparou-se o percentual de produtos retornados e reaproveitados pelo o CD no ano de 2019 com o reaproveitamento dos produtos que retornaram da regional Sul pelo milk run, percebendo-se um crescimento de $15 \%$. Assim, ao retornar os produtos com maior rapidez o reaproveitamento é maior. Esse fato é 
devido a perecibilidade do produto, das movimentações realizadas e da armazenagem praticada no parceiro logístico. Como destacado por Sathiyagothai e Saravanan (2017), a logística reversa quando aplicada as indústrias de processamento de alimento pode reduzir o desperdício de alimentos.

\section{Padronização}

Verificando-se a efetividade do projeto em relação ao padrão anterior, decidiu-se torná-lo como padrão para a regional. Assim, documentou-se todos os passos e aprendizados do projeto e criou-se um "playbook" para o setor, ou seja, criou-se uma apresentação em formato virtual que contém todos os passos que devem ser seguidos para execução dos processos. Dessa forma, esse material está disponível em uma pasta compartilhada na intranet da empresa, ficando de livre acesso aos colaboradores para a realização da gestão do conhecimento.

\section{CONCLUSÃO}

O problema que norteou o presente trabalho foi a insatisfação dos clientes com a logística de uma indústria do setor alimentício de grande porte. O problema foi investigado com o auxílio da metodologia PDCA, e criou-se a meta de "reduzir em $49 \%$ o lead time médio para o retorno das mercadorias de todas as notas emitidas no mês de outubro da regional Sul". Assim, dois pilares foram utilizados: i) o pilar processos e rotinas e ii) o pilar piloto a partir do milk run.

Com o pilar processos e rotinas obteve-se como resultado, o aumento do controle e a gestão de todas as NFDPs e suas respectivas mercadorias. Com o pilar piloto, verificou-se a viabilidade da utilização do milk run como alternativa eficiente para o processo de retorno de mercadorias em uma empresa do ramo alimentício, pois, no caso analisado notou-se ao final da implementação, maior rapidez nesse processo, maiores índices de satisfação do cliente e de reaproveitamento de produtos e, ainda, a redução de custos de frete reverso.

Ressalta-se a importância do envolvimento dos colaboradores em todo o projeto e, em especial, os colaboradores diretamente ligados à mudança de operação, sugerindo-se a organização, que o projeto implementado sirva como base para maior utilização da logística reversa como catalisadora na geração de valor ao cliente. Além disso, indica-se o presente estudo, como referência para a implementação da mesma técnica em outras regionais, tendo em vista os bons resultados obtidos. Também se propõe a investigação e melhorias nos pontos apontados como causa raízes que não foram abordados no projeto atual devido à fatores como o tempo disponível e os gastos relacionados.

A metodologia utilizada no presente trabalho e os resultados satisfatórios obtidos, servem como referência para pesquisadores da área, uma vez que o estudo apresenta e utiliza diferentes ferramentas e metodologias de fácil acesso, porém estruturadas pelos autores para a solução de problemas relacionados a área de logística reversa.

\section{REFERÊNCIAS BIBLIOGRÁFICAS}

Amaral, I., Bonato, S. V., Pereira Junior, E. F. Z., Schroeder, E. A., \& Abrita, N. (2018, outubro). O método milk-run como estratégia para redução de custos logísticos: um estudo de caso. XXXVIII Encontro Nacional de Engenharia de Produção, Maceió, AL, Brasil, 28.

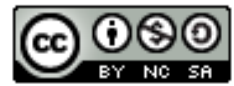


Citação (APA): de Paula, J. C. M., \& Feroni, R. de C. (2021). Utilização do ciclo PDCA e aplicação do milk run em um processo de logística reversa em uma indústria de alimentos. Brazilian Journal of Production Engineering, 7(2), 16-30.

Faria, A. R., \& Santos, A. C. (2020). Logística reversa: dificuldades e desafios para empresas de alimentos do norte do Paraná. Revista Americana de Empreendedorismo e Inovação, 2(2), 22-29.

Lei n. 12.305, de 02 de agosto de 2010. (2010). Institui a Política Nacional de Resíduos Sólidos; altera a Lei no 9.605, de 12 de fevereiro de 1998; e dá outras providências. Diário Oficial da União, DF: Congresso Nacional.

Meireles, M. (2001). Ferramentas administrativas para identificar, observar e analisar problemas (Vol. 2) (1a ed.). São Paulo: Arte \& Ciência.

Melo, M. M., \& Ribeiro, A. R. B. (2015, outubro). Utilização do método PDCA como instrumento de eliminação de falhas e de padronização de processos de um centro de distribuição em Pernambuco. XXXV Encontro Nacional de Engenharia de Produção, Fortaleza, CE, Brasil, 25.

Moreira, B. M., \& Alves, L. D. (2020, dezembro). Processo de pós-vendas: uma análise das devoluções de produtos acabados em uma empresa do ramo farmacêutico de genéricos. $X$ Congresso Brasileiro de Engenharia de Produção, Online, 10.

Moura, D. A., \& Botter, R. C. (2016). Delivery and pick-up problem transportation-milk run or conventional systems. Independent Journal of Management \& Production, 07(03), 746-770.

Ngadiman, N. I. B., Moeinaddini, M., Ghazali, J. B., \& Roslan, N. F. B. (2016). Reverse logistics in food industries: A case study in Malaysia. International Journal of Supply Chain Management, 5(3), 91-95.

Nisiyama, E. K., Oyadomari, J. C. T., Yen-Tsang, C., \& de Aguiar, A. B. (2016). O uso dos sistemas de controle gerencial e técnicas de gestão operacional. Brazilian Business Review, 13(2), 57.

Oliveira, E. A., Vieira Filho, F. C., \& Kovaleski, J. L. (2016). Investigação e análise da satisfação de clientes usando o método net promoter score para promover melhorias de produtos e processos. Revista Uningá Review, 28(3).

Peinado, J., \& Graeml, A. R. (2016). Mapeamento dos Temas Pertinentes à Gestão de Operações: uma Análise Refinada Baseada nas Percepções de Pesquisadores, Professores e Praticantes. Brazilian Business Review, 13(2), 84.

Reis, A. C., Carmo, L. F. R. R. S., \& Nishioka, I. (2008, agosto). Logística reversa e práticas correntes no setor de reciclagem. IV Congresso Nacional de Excelência em Gestão, Niterói, RJ, Brasil, 4.

Santos, N. M., Rodriguez, C., \& Tupan, L. F. D. S. (2017). A utilização do ciclo PDCA para melhoria da logística de movimentação. Revista Uningá Review, 31(1).

Sathiyagothai, B., \& Saravanan, S. (2017). Reverse logistics in food processing industries in India. International Journal of Economics \& Management Sciences, 6(2).

Setiani, P., Fiddieny, H., Setiawan, E. B., \& Etika, D. (2017, janeiro). Optimizing delivery route by applying milkrun method. Conference on Global Research on Sustainable Transport (GROST 2017), 147.

Silva, S. T. P. (2013). Logística e a gestão da qualidade: pontos para execução. Revista On-Line IPOG, 1(6).

Vergara, W. R. H., \& Yamanari, J. S. (2016). A logística reversa: Diagnóstico de processos em uma indústria de alimentos. Revista Científica on-line-Tecnologia, Gestão e Humanismo, 6(2). 